\title{
Forced hyperphasia and environmental dependency syndrome
}

\author{
Yutaka Tanaka, Martin L Albert, Hitoshi Hara, Takeshi Miyashita, Noriko Kotani
}

Neurology, Momose Clinic, 124 Shimogaito, Heguri-cho, Ikoma-gun, Nara, 636-0933 Japan Y Tanaka

Harold Goodglass Aphasia Research Center, Department of Neurology, Boston University School of Medicine, and Boston Veterans

Administration Medical Center, MA, USA

M L Albert

Department of Cerebrovascular Medicine, Yodogawa Christian Hospital, Japan

H Hara

T Miyashita

N Kotani

Correspondence to: Dr Yutaka Tanaka, Neurology, Momose Clinic, 124 Shimogaito, Heguri-cho, Ikoma-gun, Nara, 636-0933 Japan

email EZZ05540@nifty.ne.jp

Received 26 May 1999 and in revised form

8 September 1999

Accepted 17 September 1999

\begin{abstract}
A distinctive, language related fragment of the environmental dependency syndrome is described: compulsive, involuntary, environmentally dependent speaking. Because this syndrome represents the obverse of aphasia, it is named forced hyperphasia. An 84 year old woman with acute left frontal infarction was admitted to hospital with gait disturbance, forced grasp reflex, and striking imitation behaviour. After 2 weeks her imitation behaviour disappeared, but an equally striking new behaviour emerged. In the presence of others she would call out the names of objects in the room, and also call out the actions and gestures of people in the room, even though she was not asked to do so, and even though she was asked to stop. For example, if the doctor scratched his nose, she said, "The doctor is scratching his nose." Brain CT, MRI, and SPECT showed cerebral atrophy and a left superior frontal subcortical infarct. It is suggested that "forced hyperphasia" is a clinical fragment of the environmental dependency syndrome and that her compulsive, impulsive, involuntary release of spoken language resulted from the release of frontal inhibition of the complex reflex linking environmental cues to the set of motor, limbic, spatial, and linguistic associations underlying spoken language.

(F Neurol Neurosurg Psychiatry 2000;68:224-226)
\end{abstract}

Keywords: forced hyperphasia; imitation behaviour; environmental dependency syndrome

The syndromes of "imitation behaviour," "utilisation behaviour," and "environmental dependency" were described by Lhermitte and colleagues in a series of presentations, video demonstrations, and publications in the $1980 \mathrm{~s}^{1-5}$ Since then, these striking clinical phenomena have been abundantly detailed..$^{6-12}$

The term "utilisation behaviour" is applied to a peculiar pattern of actions, linked to frontal lobe dysfunction, in which patients display an exaggerated dependency on the environment for behavioural cues. When an object is placed before them they tend to act on that object (for example, use a hammer, pour water from a pitcher, write on a piece of paper), even when told not to, and even when they admit that they were told not to.

The term "imitation behaviour" refers to a condition in which patients imitate the gestures and behaviour of an examiner, even when asked not to. Imitation behaviour is considered to be a milder version of utilisation behaviour, and both are part of the more comprehensive environmental dependency syndrome.

In this report we describe a distinctive, language related fragment of the environmental dependency syndrome: compulsive, involuntary, environmentally dependent speaking. We describe an elderly woman who was unable to prevent herself from speaking about objects or events in her immediate environment, even though she was asked not to. Because this clinical phenomenon contrasts with aphasia and resembles the syndrome of compulsive writing called "forced hypergraphia", ${ }^{13}$ we propose the term "forced hyperphasia".

\section{Case report}

An 84 year old, right handed woman was admitted to the hospital for evaluation of memory impairment and gait disturbance. One month before admission she had sudden onset of right sided weakness. After that episode she developed increasing complaints of memory impairment and gait disturbance.

Positive neurological findings on admission included bilateral grasp reflexes with forced visual groping with the right hand (visual grasp reflex). She also had other evidence of frontal system dysfunction, including snout, suck, and palmomental reflexes. She had a mild right hemiparesis; she could not walk unaided; deep tendon reflexes were increased bilaterally; Babinski's sign was present on the right. Pain sensation was decreased on the right.

Orientation to time, place, and person was within normal limits. Speech output was fluent with phonemic paraphasias. Repetition was limited to short sentences. She could not follow simple spoken commands, such as "open your mouth." She had recurrent perseveration. She could read and carry out written commands. She was agraphic for Kana and Kanji. Writing to dictation for Kana letters was $80 \%$ accurate; for Kanji letters, $40 \%$; and for simple sentences, $80 \%$. Written picture descriptions were $50 \%$ accurate. Writing, both to dictation and on written picture description, was large, 

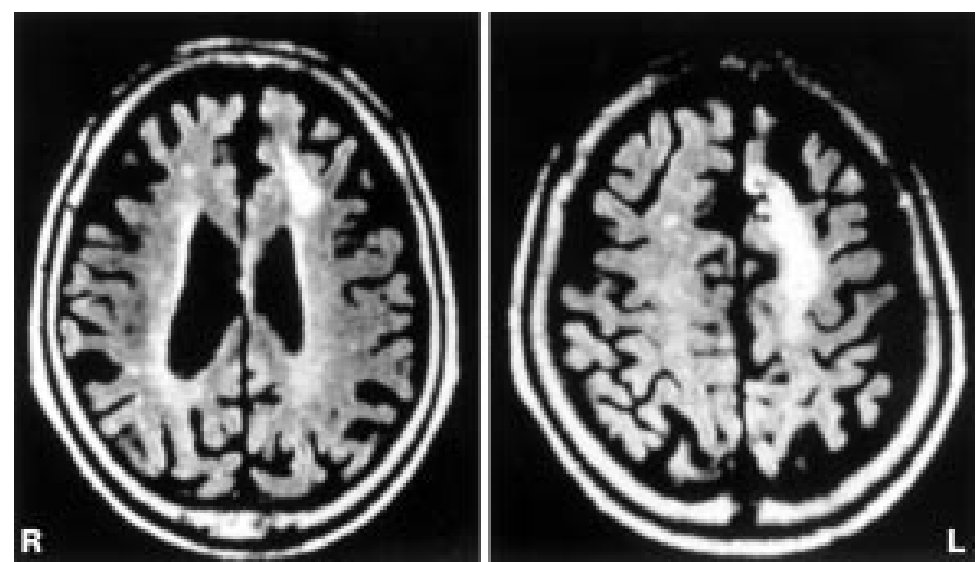

FLAIR (fluid attenuated inversion recovery) image of MRI demonstrating the left frontal subcortical infarction. crude, and poorly constructed in both Kana and Kanji. In addition to these mechanical abnormalities, there was a tendency to agrammatism, especially in the omission of function words. However, her ability to copy was virtually intact.

Mini mental state examination on the 30 th hospital day was $17 / 30$. Score on the Wechsler memory scale $(R)$ was $40 / 100$, with orientation $8 / 20$ (orientation for time and place was normal), Calculation $12 / 20$, story recall $6 / 20$, digit span $8 / 10$, and paired word recall $6 / 30$. Score on the Raven's coloured progressive matrices was 17 . The standard language test for aphasia (Japanese aphasia battery) performed on the 40th hospital day showed word finding difficulty and impairments on tests of word generation.

NEURORADIOLOGICAL EXAMINATIONS

On admission her brain CT and MRI (figure) showed, in addition to cerebral atrophy, a left superior frontal subcortical infarction. Magnetic resonance angiography (MRA) showed total occlusion of the left anterior cerebral artery, $90 \%$ stenosis of $\mathrm{M} 1$ portions bilaterally, and bilateral stenosis of posterior cerebral arteries. On the 14 th hospital day ${ }^{123} \mathrm{I}$ single photon emission tomography (SPECT) demonstrated hypoperfusion of left frontal and temporal areas.

IMITATION BEHAVIOUR AND FORCED GRASPING She displayed the forced grasp reflex behaviour commonly described in patients with frontal lobe lesions and imitation behaviour. Any objects touching her right hand, such as her bed sheets, would be grasped. Even by the 30th hospital day she still manifested visual forced grasp on the right.

Initially, she exhibited involuntary imitation behaviour. When a doctor, standing by her bedside, touched his chin, she would touch her chin. When he touched his hair, she would touch her hair. If he raised his hand, she would raise her hand. If he waved, she would wave. She imitated all behaviours of doctors and nurses in the room, even when asked not to. When asked why she did this, she said she felt she had to. When asked to stop, she was unable to prevent herself from carrying out the imitation behaviour.

FORCED HYPERPHASIA

After 2 weeks in the hospital her imitation behaviour disappeared, but, only in the presence of others, she began to call out the names of objects in the room, even though she was not asked to do so, and even after she was asked to stop. She also spoke out impulsively to name or describe actions and gestures of people in the room, even though not instructed to do so, and even after being asked to stop. For example, if a doctor touched his chin, she said, "The doctor is touching his chin." If he touched his hair, she said, "The doctor is touching his hair." If an examiner waved his hand, she said, "The doctor is waving his hand." This "speaking out" behaviour was impulsive, compulsive, involuntary, and apparently, unstoppable. She never repeated the sentences of the examiner unless so requested.

By the 30th hospital day, her forced hyperphasia disappeared.

\section{Discussion}

We think that forced hyperphasia is a language linked fragment of the environmental dependency syndrome. Patients with frontal lobe damage have been described as being "pulled to stimulus". ${ }^{14}{ }^{15}$ Imitation behaviour and utilisation behaviour seem to be complex forms of "pull to stimulus." Forced hyperphasia, first described to our knowledge by Shimomura et $a l,{ }^{16}$ probably falls within the same neurobehavioral family.

"Pull to stimulus," of course, is simply another descriptive term for a behaviour which has been difficult to explain. The best current explanation, in our opinion, is that this behaviour is a complex reflex resulting from release of frontal inhibition. Among the functions of the frontal lobes is inhibition of inappropriate motor, limbic, and spatial responses which might impulsively be released as a reaction to disturbing or irrelevant stimuli. Such behaviour, a "pull to environmental stimulus," is universal in infants. As the frontal lobes mature, instinctive, involuntary, reflex "pull to stimulus" is inhibited; the sensorimotor and association systems develop ever more complex, controlled interactions with the environment. A neurally based "social grammar" is developed whereby cognitive and emotional systems are integrated with the environment, and we develop the capacity to control our environment and plan ahead. The "social grammar" is the internalised, neurally conditioned set of rules which order and constrain interactions between and among people and their environment(s). Impulsive, inappropriate, environmentally linked, complex reflex responses are released when frontal inhibitory systems are damaged.

Why don't we see environmental dependency syndromes (forced hyperphasia, forced hypergraphia, visual grasp reflex, imitation behaviour, utilisation behaviour) more often? Most likely the "social grammar"- that is, the rules whereby the brain interacts with the envi- 
ronment is multilayered in interlocking neural nets, widely distributed throughout the brain. Focal damage to the frontal lobes without more widespread damage to the neural substrate underlying the "social grammar" may not be sufficient to cause an environmental dependency syndrome. Lhermitte made the point that "loss of intellectual control" was required for the occurrence of such behaviour. Our patient had not only the frontal lobe lesion but also damage in other portions of the brain. Shimomura $e t a l^{16}$ described what we are calling forced hyperphasia in patients with dementia of the frontal lobe type. Exploration of the neurobiology of rules whereby the brain interacts with the environment (the neurology of the "social grammar") should be a fruitful endeavour.

We thank Ms M Aoki of the Yodogawa Christian Hospital for administering the cognitive examinations.

1 Lhermitte F. Le "comportement d'utilisation" et ses relations avec les lesions des lobes frontaux. In: Actes de la Societé Française de Neurologie, 3 Dec 1981, Rev Neurol (Paris) 1981;137:846-7.

2 Lhermitte F. Un nouveau syndrome: le comportement d'utilisation et ses rapports avec les lobes frontaux. Bull Acad Natl Med (Paris) 1982;166:1073-8.
3 Lhermitte F. Utilization behaviour and its relation to lesions of the frontal lobes. Brain 1983;106:237-55.

4 Lhermitte F, Pillon B, Serdaru M. Human autonomy of the frontal lobes. Part I: imitation and utilization behavior: a neuropsychological study of 75 patients. Ann Neurol 1986; 19:326-34.

5 Lhermitte F. Human autonomy of the frontal lobes. Part II: patient behaviour in complex and social situations: the "environmental dependency syndrome". Ann Neurol 1986; 19:335-43.

6 Assal G. Un aspet du comportement d'utilisation: la dependance vis-a-vis du langage ecrit. Rev Neurol 1985; 141:493-5.

7 Shallice T, Burgess PW, Schon F, et al. The origins of utilization behaviour. Brain 1989;112:1587-98.

8 Eslinger PJ, Warner GC, Grattan LM, et al. "Frontal lobe" utilization behaviour associated with paramedian thalamic infarction. Neurology 1991;41:450-2.

9 Fukui T, Hasegawa Y, Sugita K, et al. Utilization behaviour and concomitant motor neglect by bilateral frontal lobe damage. Eur Neurol 1993;33:325-30.

10 Brazzelli M, Colombo N, Della Sala S, et al. Spared and impaired cognitive abilities after bilateral frontal damage. Cortex 1994;30:27-51.

11 Hashimoto R, Yoshida M, Tanaka Y. Utilization behavior after right thalamic infarction. Eur Neurol 1995;35:58-82.

12 De Renzi E, Cavalleri F, Facchini S. Imitation and utilization behaviour. 7 Neurol Neurosurg Psychiatry 1996; 61:396-400.

13 van Vugt $\mathrm{P}$, Paquier $\mathrm{P}$, Kees L, et al. Increased writing activity in neurological conditions: a review and clinical study. $\mathcal{F}$ Neurol Neurosurg Psychiatry 1996;61:510-14.

14 Hecaen H, Albert ML. Human neuropsychology. New York: Wiley, 1978 .

15 Stuss DT, Benson DF. The frontal lobes. New York: Raven Press, 1986.

16 Shimomura T, Ikeda M, Imamura T, et al. Forced language response of frontal dementia [abstract]. Fapan fournal of Neuropsychology 1995;11:257. (In Japanese.) 